This item was submitted to Loughborough's Research Repository by the author.

Items in Figshare are protected by copyright, with all rights reserved, unless otherwise indicated.

\title{
Are parenting style and controlling feeding practices related?
}

PLEASE CITE THE PUBLISHED VERSION

http://dx.doi.org/10.1016/j.appet.2007.10.003

\section{PUBLISHER}

(c) Elsevier

VERSION

AM (Accepted Manuscript)

LICENCE

CC BY-NC-ND 4.0

\section{REPOSITORY RECORD}

Blissett, Jacqueline, and Emma Haycraft. 2019. "Are Parenting Style and Controlling Feeding Practices Related?”. figshare. https://hdl.handle.net/2134/11325. 
This item was submitted to Loughborough's Institutional Repository (https://dspace.lboro.ac.uk/) by the author and is made available under the following Creative Commons Licence conditions.

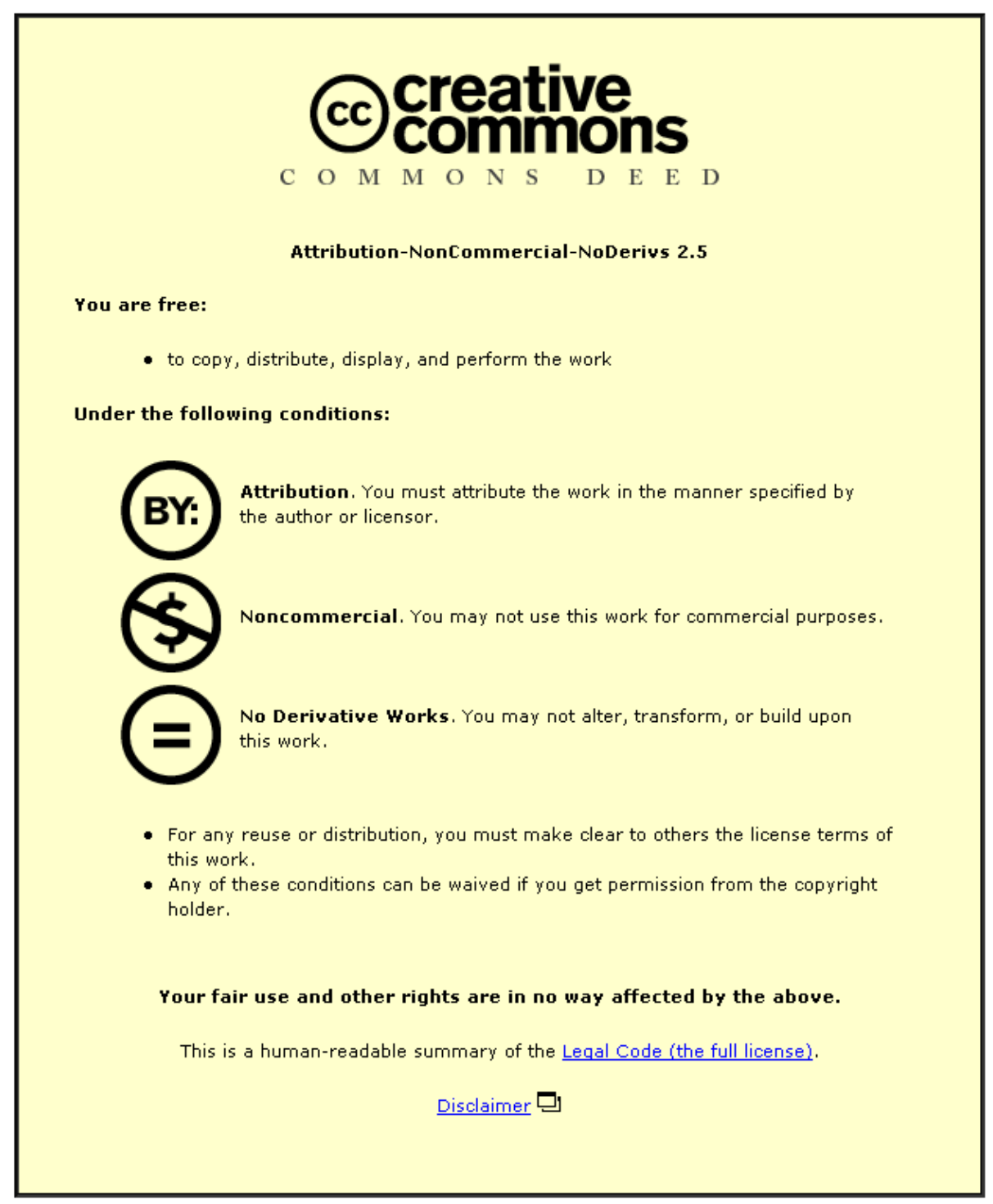

For the full text of this licence, please go to: http://creativecommons.org/licenses/by-nc-nd/2.5/ 


\section{ARE PARENTING STYLE AND CONTROLLING FEEDING PRACTICES RELATED?}

Blissett, J., Ph.D.* \& Haycraft, E, Ph.D.

School of Psychology

University of Birmingham, UK.

\footnotetext{
* Please address all correspondence to Dr J Blissett, School of Psychology, University of Birmingham, Edgbaston Birmingham UK email j.blissett@bham.ac.uk Tel. 0044 1214143340 Fax 00441214144897
}

RUNNING HEAD: PARENTING AND FEEDING STYLE 


\begin{abstract}
This study examined the relationships between parenting styles, feeding practices and BMI in a non-clinical sample of mothers and fathers of UK preschool children. Ninety-six co-habiting parents of 48 children (19 male, 29 female, mean age 42 months), completed a series of self report questionnaires assessing parenting style, feeding practices, eating psychopathology and a range of demographic information. There were no relationships between authoritarian parenting and controlling feeding practices. Authoritative parenting was positively associated with monitoring. Permissive parenting was associated with greater use of pressurising feeding practices and fewer reports of monitoring. There were no relationships between parenting style and child BMI Z scores. The inconsistent and indulgent parenting practices evidenced by permissive parents may extrapolate into dysfunctional feeding practices. Authoritative parenting is associated with more healthful feeding practices. Parenting style may not have a direct impact on child BMI until child food selection and consumption becomes more autonomous.
\end{abstract}

Keywords

Parenting, control, child, eating, anorexia, bulimia, body dissatisfaction, fathers 


\section{ARE PARENTING STYLE AND CONTROLLING FEEDING}

PRACTICES RELATED?

Given the concern about the increasing prevalence of overweight and obesity in children (e.g. Reilly \& Dorosty, 1999), research investigating modifiable predictors of excessive weight gain in infancy and childhood is an important priority. One such predictor that has received considerable recent research attention is that of parental feeding style. Applying a moderate level of control, such as monitoring unhealthy snack intake, is a healthy and functional strategy for parents to apply in order to manage their children's food intake appropriately. However, high levels of control over children's food intake have been linked with subsequent disinhibited eating (e.g. Fisher \& Birch, 1999; Birch, Fisher \& Davison, 2003) and child weight or BMI at each end of the spectrum (e.g. Faith et al., 2003; Farrow \& Blissett, 2006a). Whilst there is some variation in the findings concerning the degree of negative impact that excessive control has on child weight (see Clark, Goyder, Bissell, Blank \& Peters, 2007; Montgomery, Jackson, Kelly \& Reilly, 2006), longitudinal research suggests that highly restrictive feeding practices have been most consistently associated with child weight gain (e.g. Clark et al., 2007), and monitoring feeding practices have been associated with slower weight gain (e.g. Faith et al., 2004). Factors such as genetic risk, ethnicity and cultural practices, socioeconomic status, and education may moderate the effects of feeding practices on weight outcome (e.g. Clark et al., 2007; Faith et al., 2003; Faith et al., 2004).

Some authors have begun to investigate whether the feeding style exhibited by a parent is reflective of a broader style of parenting, or is specific to the feeding domain. There is a literature which suggests that parents' feeding practices are 
broadly linked with their parenting styles (Hughes, Power, Fisher, Mueller \& Nicklas, 2005), and that parenting styles are good predictors of children's BMI, fruit and vegetable intake, healthier eating, physical activity and sedentary behaviours (e.g. Rhee, Lumeng, Appugliese, Kaciroti \& Bradley, 2006; Kremers, Brug, de Vries \& Engels, 2003; Schmitz et al., 2002).

In the context of child weight, Rhee et al. (2006) demonstrated that children of authoritarian, permissive and neglectful mothers were significantly more likely to be overweight than the children of mothers with an authoritative style. Authoritarian parenting carried the highest risk, with children of authoritarian parents being five times more likely to be overweight than children of authoritative parents, suggesting that a strict, unresponsive family environment may be particularly associated with excessive weight gain in childhood. This study controlled for the influence of a variety of other factors which may influence these outcomes such as gender, ethnicity, education, income, marital status and other behaviour problems. None of these factors affected the relationship between parenting style and weight outcome. Whilst this study highlighted the need to address broader parenting issues to understand the processes underlying childhood overweight, it did not assess parental feeding style per se. Therefore it was unclear from this study whether the apparent effects of less adaptive parenting style on early weight gain are a product of, for example, overeating as a way of coping with stress or other negative emotions, or may actually be explained by specific feeding styles associated with authoritarian parenting, such as a focus on external cues for the initiation and cessation of eating.

The suggestion that feeding styles may be an extension of more generic parenting styles is supported by a study by Hughes and colleagues who demonstrated that more controlling parenting styles were associated with more authoritarian feeding 
styles, while authoritative feeding styles were related to greater parental responsiveness to children (Hughes et al., 2005). Hughes et al. also demonstrated that authoritative parents were more likely to monitor their children's food intake than were less authoritative parents, and that children with indulgent parents had a higher BMI than did children with authoritarian parents. Moreover, Duke and colleagues found that parental pressure to eat was related to authoritarian parenting in parents with 7-year-old sons (Duke, Bryson, Hammer \& Agras, 2004), and several studies have demonstrated that children and adolescents consume greater levels of fruit and vegetables if they have authoritative parents, or parents who use an authoritative feeding style (e.g. Kremers et al., 2003; Patrick, Nicklas, Hughes \& Morales, 2005). Parenting style may also influence the effectiveness of obesity intervention programmes; a recent study suggested that permissive parenting style negatively impacted on children's weight loss in family based interventions (Golan, 2006).

However, some researchers have not found support for the links between child BMI, parenting style and feeding practices. For example, Brann and Skinner (2005) did not find significant differences in the parenting styles of children in low or high BMI groups, and did not find a relationship between feeding practices and parenting styles. Furthermore, Montgomery et al. (2006) failed to find significant evidence for a link between parental control and child weight status or energy intake in a UK sample of 4-year-old children. This equivocality in the literature warrants further investigation. Some of the inconsistencies in the literature may be explained by differences between study methods, measures and sample sizes, as well as sample differences in participants' cultural background, education, socioeconomic status, age and BMI status. However, to date few studies in this domain have attempted to control for other factors which have been established as predictors of controlling 
feeding practices, including breastfeeding, eating psychopathology, and parent or child BMI. Mothers who breastfed their children have been shown to exhibit and report lower levels of subsequent control over their children's eating (Farrow \& Blissett, 2006b; Fisher, Birch, Smiciklas-Wright \& Picciano, 2000; Taveras et al., 2004). Both mothers and fathers with non-clinical levels of eating psychopathology have been shown to be more controlling over their children's eating, particularly their daughters' food intake (Blissett, Meyer \& Haycraft, 2006), and mothers with eating disorders have been shown to exhibit more maladaptive, intrusive and controlling behaviour at mealtimes (e.g. Cooper, Whelan, Woolgar, Morrell \& Murray, 2004). Maternal eating disorder pathology has also been related to less sensitive, more controlling parenting styles outside of the context of mealtimes (Stein et al., 2001), suggesting one alternative explanation for the link between parenting and feeding styles. Whilst children's BMI has been linked with controlling feeding practices, findings are inconsistent (see Brann \& Skinner, 2005; Clark et al., 2007; Montgomery et al., 2006). Furthermore, obese parents have been demonstrated to exhibit less control of their children's food intake (Wardle, Sanderson, Guthrie, Rapoport \& Plomin, 2002), whilst other studies have not found a link between parental BMI and child feeding practices (Faith et al., 2003). Therefore, if we are to examine the nature of the relationship between parenting style and feeding style, such factors need to be examined and/or controlled for in our analyses.

In addition to the scarcity of other predictors of controlling feeding being included in these pieces of research, few authors have included fathers in their studies of the relationship between parenting and feeding styles. Fathers are important members of feeding interactions and their contribution to mealtime practices is frequently overlooked. However, studies that have included fathers have 
demonstrated that whilst fathers are less likely to be responsible for feeding their children, they do not report different levels of feeding practices and are just as likely to exhibit controlling feeding practices as mothers (Blissett et al., 2006). Therefore, this paper aimed to examine the relationships between self reported parenting styles and feeding styles in mothers and fathers. Specifically, the study aimed to examine the relationships between feeding practices, parenting style and child BMI, whilst controlling for potential influences on this relationship including parent BMI, eating pathology and breastfeeding history, and a range of demographic information. We hypothesised that higher child BMI would be associated with more controlling feeding practices, and less adaptive parenting styles (authoritarian, permissive), lower SES and education levels, and shorter duration of breastfeeding. We hypothesised that less adaptive parenting styles (authoritarian, permissive) would be associated with more dysfunctional feeding practices, (i.e. higher levels of pressure to eat and restriction, lower levels of monitoring), and more authoritative parenting would be associated with more functional feeding practices (higher levels of monitoring, lower levels of pressure to eat and restriction). Finally we hypothesised that the relationships between controlling practices and parenting styles would be attenuated, but not eliminated, by partialling out significant control covariates.

\section{Method}

\section{Participants}

Forty-eight families, constituting 96 parents (48 mothers and 48 fathers) of 19 male and 29 female children (mean age 41.6 months, $\mathrm{SD}=9.0$, range 24-59) were recruited through pre-school nurseries in the West Midlands and Cambridge, UK. Girls had a mean BMI of 16.3 ( $\mathrm{SD}=2.2$, range 13.2-20.3), and boys had a mean BMI 
of 15.7 ( $\mathrm{SD}=2.5$, range 12.7-21.4). BMI Z scores were also calculated using the Child Growth Foundation's British 1990 growth references for body mass indices to adjust for age and gender (Child Growth Foundation, 1996). Boys' mean BMI Z score $=.49$, range -3.46 to 3.04; girls' mean $\mathrm{BMI} \mathrm{Z} \mathrm{score}=.25$, range -2.18 to 2.51. Children who were overweight or obese were also identified using Cole et al.'s standard definitions of overweight and obesity corrected for age and gender (Cole, Bellizi, Flegal \& Dietz, 2000). This demonstrated that $23 \%$ of the children in the sample were overweight or obese (10\% classified as overweight, $13 \%$ as obese). Overweight and obese children did not differ significantly from those children who were not overweight on any of the study's outcome variables. Boys and girls did not significantly differ on any of the study's variables. Thirty-eight of the 48 sets of parents were married and the remainder were cohabiting. The mean duration of the parents' relationship was 11.7 years $(\mathrm{SD}=4.7$, range $=3.75-23$ years $)$. The mothers' mean age was 35 years $(\mathrm{SD}=4.3$, range 23-46 years) and the fathers' mean age was 37 years $(\mathrm{SD}=5.0$, range 26-49 years). Paternal mean BMI was $25.9(\mathrm{SD}=3.0$, range 18.1-32.4) and maternal mean BMI was 24.6 ( $\mathrm{SD}=4.7$, range 19.2-39.7). Forty-five of the 48 fathers were the child's biological parent. The majority of families had 2 children, with a range of 1 to 7. The children in this study spent an average of 3 days a week ( 6.3 sessions out of a potential of 10; 5 mornings, 5 afternoons) in nursery or other day-care separate from both parents $(\mathrm{SD}=2.8$, range 2-10). Mothers reported a mean breastfeeding duration of 9.7 months ( $\mathrm{SD}=8.9$, range $0-42$ months). Six of the mothers in this study did not breastfeed. Mothers reported a mean of 5 years education post $16(\mathrm{SD}=2.5$, range 0 10 ), and fathers reported similarly (mean $=5.1, \mathrm{SD}=3.8$, range $0-18$ ). Seventy-seven percent of mothers and $79 \%$ of fathers were classified as social class 1 according to 
the National Statistics Socio-Economic Classification self-coded method (NS-SEC; Office for National Statistics, 2005).

Measures

\section{Child Feeding Questionnaire (CFQ; Birch et al., 2001)}

Parents completed three subscales of the CFQ, a self-report measure of parents' feeding practices: Monitoring (the extent to which each parent keeps track of unhealthy foods); Restriction (parents' control of their child's eating by restriction of type and amount of food, use of foods as rewards); and Pressure to Eat (the extent to which parents attempt to increase their children's consumption of food in terms of type or amount). The CFQ has been found to display adequate validity and reliability (Birch et al., 2001).

\section{Eating Disorder Inventory-2 (EDI-2; Garner, 1991)}

The EDI-2 is a 91-item measure based on the original EDI, which has been validated for use with both men (Spillane, Boerner, Anderson \& Smith, 2004) and women (Garner, 1991). Three eating subscales were administered: Drive for Thinness; Bulimia; and Body Dissatisfaction. The EDI-2 has been found to display good test-retest reliability, internal consistency and validity (Garner, 1991).

Parenting Styles and Dimensions Questionnaire (PSDQ; Robinson, Mandleco, Olsen \& Hart, 2001)

The PSDQ assesses how often a parent exhibits certain behaviours towards his/her child. It has 32 items contributing to three factors: Authoritative Parenting 
Style (measuring parent-child warmth and connection, parental use of reasoning, inductive parenting and autonomy granting); Authoritarian Parenting Style (measuring physical coercion, verbal hostility and non-reasoning/punitive disciplinary practices); and Permissive Parenting Style (measuring parental indulgence and inconsistency). Four 'physical coercion' questions contributing to the Authoritarian factor were removed from the questionnaire prior to distribution due to insufficient provision for dealing with reports of corporal punishment or child abuse. The PSDQ has been shown to demonstrate adequate reliability and validity (Robinson et al., 2001)

\section{Data Analysis}

Descriptive statistics were calculated for the sample. One way ANOVA was used to examine differences between mothers and fathers of boys and girls in the variables within this study. Two-tailed Pearson's correlation coefficients were calculated between parental feeding practices, parenting styles, child BMI Z score and the remaining study variables, to examine the need to control for covariates in the final analysis. Finally, one-tailed partial correlation coefficients were calculated to examine the relationship between parenting style and feeding practices controlling for significant covariates.

\section{Results}

Descriptive statistics:

Table 1 demonstrates the descriptive statistics for the sample, and the differences between the groups. There were few significant differences between the groups, with the exception of monitoring and body dissatisfaction. Post-hoc Tukey's 
tests demonstrated that mothers carried out significantly more monitoring than fathers, irrespective of the gender of their child. Similarly, mothers reported greater levels of body dissatisfaction than did fathers, irrespective of the gender of their child. There were no differences between male and female children in the study's outcome measures. Because of the relatively few differences between groups, the samples were collapsed to maintain power for subsequent analyses.

Table 1 about here

To ascertain which variables would need to be controlled for in the final analyses, a series of Pearson correlation coefficients were calculated between parental reports of feeding practices, parenting styles and child BMI Z score with a range of potentially co-varying factors (including parental BMI, age, duration of parental relationship, socioeconomic status, years of parental education, number of children in the family, length of breastfeeding in infancy, amount of time the child spends at nursery in an average week, number of meals and snacks parents spend with child in a week), and parental eating psychopathology. Table 2 presents these correlation coefficients.

Table 2 about here

Child age, parental age, parental BMI, length of parental relationship, number of children in the family, length of breastfeeding in infancy and parental body 
dissatisfaction were not significantly correlated with either feeding practices or parenting style and were therefore not controlled for in subsequent analyses.

Monitoring feeding practices were positively correlated with the number of meals and snacks the parent spent with their child in a typical week. Child BMI Z score was negatively correlated with pressure to eat but no aspect of parenting style. Restrictive feeding practices were negatively correlated with the number of years of education a parent had post-16. Authoritative parenting was associated with higher SES, more post-16 education, eating a greater number of meals and snacks with one's child, and lower drive for thinness and bulimia scores. Authoritarian parenting was associated with higher drive for thinness and bulimia scores. Permissive parenting was associated with fewer years of education post-16, eating fewer meals and snacks with one's child, the child spending greater proportion of their time at nursery, and higher drive for thinness scores.

Next, one-tailed partial correlation coefficients were calculated to examine the relationships between feeding practices and parenting style controlling for relevant covariates. Relevant covariates were defined as any variable that correlated with the feeding practice or parenting style under examination (see Table 2). For example, the partial correlation calculated to examine the relationship between pressure to eat and authoritarian parenting controlled for the covariates of child BMI Z score, parental drive for thinness and parental bulimia. Table 3 demonstrates the relationships between feeding practices and parenting styles, both before and after controlling for the relevant covariates.

Table 3 about here 
Prior to controlling for covariates, monitoring feeding practices were positively correlated with authoritative parenting styles, and negatively correlated with permissive parenting styles. Both pressurising and restrictive feeding practices were positively correlated with permissive parenting styles. Authoritarian parenting was not correlated with any feeding practices. After partialling out covariates, monitoring was still significantly correlated with authoritative and permissive parenting and remained uncorrelated with authoritarian parenting. Pressure to eat remained uncorrelated with authoritative and authoritarian parenting and remained a significant correlate of permissive parenting. Restriction remained uncorrelated with authoritative and authoritarian parenting but became a non-significant correlate of permissive parenting.

\section{Discussion}

This paper aimed to examine the relationships between self reported parenting styles, feeding styles and child BMI in mothers and fathers. Permissive parenting style was related to maladaptive feeding practices and authoritative parenting style was related to monitoring of children's unhealthy food intake, but parenting styles were not related to child weight in this sample.

Support was found for the hypothesis that permissive parenting style would be related to controlling feeding practices. The measure of permissive parenting used here can be interpreted to report on parental use of indulgent and/or inconsistent parenting practices (e.g. 'states punishments to child and does not actually do them'). Permissive parenting, characterised by an inability to apply and enforce appropriate boundaries, may predispose children to an inability to self regulate their behaviour, and this may extrapolate to the domain of eating. Inconsistent parenting practices may 
also be particularly salient in the context of feeding. For example, pressurising feeding practices were associated with more permissive, indulgent or inconsistent parenting. Parents who regularly apply pressure to eat (e.g. 'eat up your vegetables or you cannot have dessert') may also frequently fail to adhere to this self imposed rule as they have greater difficulties with application of appropriate boundaries in the broader context of parenting, and may be more likely to base rules concerning food acceptance at specific mealtimes on children's emotional reactions. Consistent with this theory is the finding that monitoring, a relatively healthy, covert practice, associated with reduced risk of weight gain in the longer term (Faith et al., 2004), was associated with less permissive, indulgent or inconsistent parenting. Overall, this study's findings concerning the negative relationship between permissive parenting and healthy feeding practices help to explain previous literature which has suggested that permissive parenting may reduce the effectiveness of interventions with obese children (Golan, 2006).

We did not find convincing evidence for a link between restrictive feeding and permissive parenting, as this relationship appeared to be explained by covariance with parental education, as well as drive for thinness, and the amount of time the child spent at nursery or ate with their parents, because once these covariates were controlled for, the previously significant relationship disappeared. Furthermore, we found no support for the hypothesis that authoritarian parenting would be related to more controlling feeding practices. Whilst previous research has suggested that more authoritarian parents use more pressurising feeding practices (e.g. Duke et al., 2004) this was not found to be the case in this sample, and indeed we found few correlates of authoritarian parenting in this sample, with the exception of psychological distress as evidenced by drive for thinness and bulimia. However it is important to note that 
because we had to remove the physical coercion dimension from this questionnaire, the measure of authoritarian parenting we have used here may strictly be interpreted as a measure of parental verbal hostility and non-reasoning punitiveness, rather than a classically interpreted authoritarian parenting style.

Support was found for the hypothesis that more adaptive feeding practices would be related to less dysfunctional parenting styles in that monitoring was associated with authoritative parenting. This supports the findings of previous studies with US samples (e.g. Hughes et al., 2005). It appears that in the context of a warm, supportive parent-child relationship, which facilitates autonomy within appropriate boundaries, parents are more likely to keep a mental note of their children's unhealthy food intake, but they do not tend to engage in overtly restrictive or pressurising feeding practices. Whilst this may be partly explained by the fact that more authoritative parents also reported spending more time eating with their children, had less eating pathology, greater education, and higher socioeconomic status, when these factors were controlled for, the relationship between monitoring and authoritative parenting remained significant. Monitoring may be interpreted as the rational outcome of an adaptive concern for their children to remain healthy, and may promote healthier eating and feeding behaviour within the family (e.g. buying fewer unhealthy foods, or modelling consumption of healthy foods). It could be suggested that the extrapolation of effective parenting practices to the feeding domain may facilitate children's self regulation of eating behaviour and may foster reduced need for parental intervention in the control of food choice and intake. Observational, longitudinal work is required to examine these suggestions in more depth.

Child BMI Z score was linked to parental application of control in that lighter children received greater pressure to eat. However, child BMI was not a correlate of 
any other variable in this study. In this non-clinical group, there was no association between parenting style and weight outcome, supporting the findings of Brann and Skinner (2005). Furthermore, traditional predictors of child BMI (e.g. SES, breastfeeding history, parental BMI) were not significant correlates of child BMI in this small sample of UK based, non-clinical, middle class, 3.5 year old children. However, this finding is consistent with other studies which have suggested that parental BMI and child BMI do not necessarily show high correlations while children are in the preschool years (e.g. Whitaker, Deeks, Baughcum \& Specker, 2000), that parental BMI does not necessarily relate to child feeding practices (Faith et al., 2003), that the long term effects of breastfeeding on weight outcome may be relatively small (Owen et al., 2005) and that whilst children of lower SES have a higher risk of being overweight, this is not a problem which is limited to members of lower socioeconomic groups (Stamatakis, Primatesta, Chinn, Rona \& Falascheti, 2005).

Furthermore, that we found no evidence of a cross sectional relationship between parenting style and weight outcome at 3.5 years does not mean that parenting is not an important predictor of weight outcome in the longer term. Indeed Rhee et al., (2006) demonstrated that parenting style at 4 years predicted subsequent weight status at 7 years, lending credence to this suggestion. Many clinical studies have demonstrated the importance of adding parenting input to intervention studies for childhood obesity (e.g. Golan, 2006). It may be the case that it is in the preschool years that children learn the eating habits and emotional relationships with food which then predict their disinhibited eating and subsequent weight gain in later childhood, when food choice and eating behaviour becomes more autonomous (e.g. Birch et al., 2003). 
There were few differences between mothers and fathers or girls and boys in this sample with the exception that mothers reported greater monitoring of their children's food intake irrespective of their children's gender, and were more dissatisfied with their bodies than are fathers. That we found few gender differences in the sample supports previous studies which have suggested that mothers and fathers do not differ radically in their use of pressurising and restrictive feeding practices or treat their male and female children differently in feeding settings and that mothers tend to report greater monitoring and body dissatisfaction than do fathers (Blissett et al., 2006). However, this does not mean that there are not different relationships between the variables in this study for male and female children, but a much larger sample would be required to examine these relationships separately for mothers and fathers of girls and boys.

Similarly, we found few relationships between eating psychopathology and feeding practices, despite much previous research with similar samples which has demonstrated strong links between these factors (e.g. Blissett et al., 2006). However we did find strong links between eating pathology and parenting style, with authoritative parenting negatively relating to eating pathology, and both types of nonoptimal parenting being reported by parents with greater eating pathology. This finding supports the work of Stein and colleagues who have suggested that eating disordered mothers have significant problems with parenting their children both within and external to feeding interactions (Stein et al., 2001) and could be a fruitful area for further work.

There were a number of limitations to this study. The small, skewed sample prevents generalisation of findings to other ethnic or demographic groups and the findings of this study may not generalise to a clinical sample of overweight or obese 
children and their parents. The reliability of the measures was acceptable for this sample but the study relies on self report methods, and observational and longitudinal methods are required to investigate the relative impact of parenting style on both feeding practice and weight gain in the longer term. However, despite these problems, this study has demonstrated that parenting style may be an important correlate of feeding practice, and that parents who have difficulties with setting appropriate limits, who are inconsistent or indulgent in their parenting practices, may be more likely to evidence unhealthy feeding practices that may ultimately impede the child's development of appropriate self-regulation of food intake. Interventions that are designed to involve parents as the agents of change may benefit from the inclusion of broader parenting skills in their programmes because these may facilitate appropriate parental guidance and involvement in feeding interactions. 


\section{References}

Birch, L. L., Fisher, J. O., \& Davison, K. K. (2003). Learning to overeat: Maternal use of restrictive feeding practices promotes girls' eating in the absence of hunger. American Journal of Clinical Nutrition, 78, 2, 215-220.

Birch, L. L., Fisher, J. O., Grimm-Thomas, K., Markey, C. N., Sawyer, R., \& Johnson, S. L. (2001). Confirmatory factor analysis of the Child Feeding Questionnaire: A measure of parental attitudes, beliefs and practices about child feeding and obesity proneness. Appetite, 36, 201-210.

Blissett, J., Meyer, C., \& Haycraft, E. (2006). Maternal and paternal controlling feeding practices with male and female children. Appetite, 47, 2, 212-219.

Brann, L. S. \& Skinner, J. D. (2005). More controlling child-feeding practices are found among parents of boys with an average body mass index compared with parents of boys with a high body mass index. Journal of the American Dietetic Association, 105, 1411-1416.

Child Growth Foundation. (1996). Cross Sectional Stature and Weight Reference Curves for the UK. London, United Kingdom: Child Growth Foundation.

Clark, H.R., Goyder, E., Bissell, P., Blank, L., \& Peters, J. (2007). How do parents' child-feeding behaviours influence child weight? Implications for childhood obesity policy. Journal of Public Health 29, 132-141. 
Cole, T. J., Bellizzi, M. C., Flegal, K. M., \& Dietz, W. H. (2000). Establishing a standard definition for child overweight and obesity worldwide: international survey. British Medical Journal, 320, 1-6.

Cooper, P. J., Whelan, E., Woolgar, M., Morrell, J., \& Murray, L. (2004). Association between childhood feeding problems and maternal eating disorder: Role of the family environment. British Journal of Psychiatry, 184, 210-215.

Duke, R. E., Bryson, S., Hammer, L. D., \& Agras, W. S. (2004). The relationship between parental factors at infancy and parent-reported control over children's eating at age 7. Appetite, 43, 247-252.

Faith, M. S., Heshka, S., Keller, K. L., Sherry, B., Matz, P. E., Pietrobelli, A., \& Allison, D.B. (2003). Maternal-child feeding patterns and child body weight Findings from a population-based sample. Archives of Pediatrics and Adolescent Medicine, 157, 9, 926-932.

Faith, M. S., Berkowitz, R. I., Stallings, V. A., Kerns, J., Storey, M., \& Stunkard, A. J. (2004). Parental feeding attitudes and styles and child body mass index: Prospective analysis of a gene-environment interaction. Pediatrics, 114, 4, e429-e436.

Farrow, C. \& Blissett, J. (2006a). Does maternal control during feeding moderate early infant weight gain? Pediatrics, 118, 293-298. 
Farrow, C. \& Blissett, J. (2006b). Breast-feeding, maternal feeding practices and mealtime negativity at one year. Appetite, 46, 49-56.

Fisher, J. O. \& Birch, L. L. (1999). Restricting access to palatable foods affects children's behavioral response, food selection, and intake. American Journal of Clinical Nutrition, 69, 1264-1272.

Fisher, J. O., Birch, L. L., Smiciklas-Wright, H., \& Picciano, M. F. (2000). Breastfeeding through the first year predicts maternal control in feeding and subsequent toddler energy intakes. Journal of the American Dietetic Association, 100, 6, 641-646.

Garner, D. M. (1991). Eating Disorders Inventory 2: Professional manual. Odessa, FL: Psychological Assessment Resources.

Golan, M. (2006). Parents as agents of change in childhood obesity - from research to practice. International Journal of Pediatric Obesity, 1, 66-76.

Hughes, S. O., Power, T. G., Fisher, J. O., Mueller, S., \& Nicklas, T. A. (2005). Revisiting a neglected construct: parenting styles in a child-feeding context. Appetite, 44, 83-92.

Kremers, S. P., Brug, J., de Vries, H., \& Engels, R. C. M. E. (2003). Parenting style and adolescent fruit consumption. Appetite, 41, 43-50. 
Montgomery, C., Jackson, D. M., Kelly, L. A., \& Reilly, J. J. (2006). Parental feeding style, energy intake and weight status in young Scottish children. British Journal of Nutrition, 96, 1149-1153.

Office For National Statistics (2005). The National Statistics Socio-Economic

Classification user manual. (http://www.statistics.gov.uk/methods_quality/ns_sec).

Owen, C. G., Martin, R. M., Whincup, P. H., Davey-Smith, G., Gillman, M. W., \& Cook, D. G. (2005). The effect of breastfeeding on mean body mass index throughout life: a quantitative review of published and unpublished observational evidence (1-3). American Journal of Clinical Nutrition, 82, 1298-1307.

Patrick, H., Nicklas, T. A., Hughes, S. O., \& Morales, M. (2005). The benefits of authoritative feeding style: Caregiver feeding styles and children's food consumption patterns. Appetite, 44, 243-249.

Reilly, J. J. \& Dorosty, A. R. (1999). Epidemic of obesity in UK children. Lancet, $354,1874-1875$.

Rhee, K. E., Lumeng, J. C., Appugliese, D. P., Kaciroti, N., \& Bradley, R. H. (2006). Parenting styles and overweight status in first grade. Pediatrics, 117, 2047-2054.

Robinson, C. C., Mandleco, B., Olsen, S. F., \& Hart, C. H. (2001). The Parenting Styles and Dimensions Questionnaire (PSQD). In B. F. Perlmutter, J. Touliatos, \& G. 
W. Holden (Eds.), Handbook of family measurement techniques: Vol. 3. Instruments \& index (pp. 319 - 321). Thousand Oaks: Sage.

Schmitz, K. H., Lytle, L. A., Phillips, G. A., Murray, D. M., Birnbaum, A. S., \& Kubik, M. Y. (2002). Psychosocial correlates of physical activity and sedentary leisure habits in young adolescents: The teens eating for energy and nutrition at school study. Preventive Medicine, 34, 266-278.

Spillane, N. S., Boerner, L. M., Anderson, K. G., \& Smith, G. T. (2004).

Comparability of the Eating Disorder Inventory-2 between women and men. Assessment, 11, 1, 85-93.

Stamatakis, E., Primatesta, P., Chinn, S., Rona, R., \& Falascheti, E. (2005).

Overweight and obesity trends from 1974 to 2003 in English children: what is the role of socioeconomic factors? Archives of Disease in Childhood, 90, 999-1004.

Stein, A., Woolley, H., Murray, L., Cooper, P. J., Cooper, S., Noble, F., Affonso, N., \& Fairburn, C.G. (2001). Influence of psychiatric disorder on the controlling behaviour of mothers with one-year-old infants: A study of women with maternal eating disorder, postnatal depression and a healthy comparison group. British Journal of Psychiatry, 179, 157-162.

Taveras, E. M., Scanlon, K. S., Birch, L. L., Rifas-Shiman, S. L., Rich-Edwards, J. W., \& Gillman, M. W. (2004). Association of breastfeeding with maternal control of infant feeding at age 1 year. Pediatrics, 114, 5, e577-e583. 
Wardle, J., Sanderson, S., Guthrie, C. A., Rapoport, L., \& Plomin, R. (2002). Parental feeding style and the intergenerational transmission of obesity risk. Obesity Research, $10,6,453-462$.

Whitaker, R. C., Deeks, C. M., Baughcum, A. E., \& Specker, B. L. (2000). The relationship of childhood adiposity to parent Body Mass Index and eating behavior. Obesity Research, 8, 3, 234-240. 
Table 1: Descriptive statistics and group difference analyses for mothers and fathers of boys and girls.

\begin{tabular}{|c|c|c|c|c|c|c|}
\hline & $\begin{array}{l}\text { MG } \\
\text { Mean } \\
(\mathrm{SD})\end{array}$ & $\begin{array}{l}\text { MB } \\
\text { Mean } \\
(\mathrm{SD})\end{array}$ & $\begin{array}{l}\text { FG } \\
\text { Mean } \\
(\mathrm{SD})\end{array}$ & $\begin{array}{l}\text { FB } \\
\text { Mean } \\
(\mathrm{SD})\end{array}$ & $\begin{array}{l}\text { ANOVA } \\
\mathrm{df}=3,92 \\
\mathrm{~F}=\end{array}$ & $\begin{array}{l}\text { Post hoc } \\
\text { Comparison } \\
\text { (Tukey HSD) }\end{array}$ \\
\hline Child age & $\begin{array}{l}41.7 \\
(8.59)\end{array}$ & $\begin{array}{l}41.4 \\
(9.83)\end{array}$ & $\begin{array}{l}41.8 \\
(8.59)\end{array}$ & $\begin{array}{l}41.4 \\
(9.83)\end{array}$ & .014 & NS \\
\hline Child BMI & $\begin{array}{l}16.4 \\
(2.17)\end{array}$ & $\begin{array}{l}15.7 \\
(2.47)\end{array}$ & $\begin{array}{l}16.8 \\
(2.36)\end{array}$ & $\begin{array}{l}15.2 \\
(2.60)\end{array}$ & 1.32 & NS \\
\hline Parental age & $\begin{array}{l}34.8 \\
(4.05)\end{array}$ & $\begin{array}{l}35.6 \\
(4.68)\end{array}$ & $\begin{array}{l}36.5 \\
(4.90)\end{array}$ & $\begin{array}{l}38.3 \\
(5.09)\end{array}$ & 2.16 & NS \\
\hline Parental BMI & $\begin{array}{l}25.0 \\
(4.71)\end{array}$ & $\begin{array}{l}23.9 \\
(4.66)\end{array}$ & $\begin{array}{l}25.8 \\
(2.68)\end{array}$ & $\begin{array}{l}25.9 \\
(3.64)\end{array}$ & 1.06 & NS \\
\hline Monitoring & $\begin{array}{l}4.37 \\
(.87)\end{array}$ & $\begin{array}{l}4.54 \\
(.54)\end{array}$ & $\begin{array}{l}3.29 \\
(1.08)\end{array}$ & $\begin{array}{l}3.68 \\
(.74)\end{array}$ & $11.47 *$ & $\mathrm{MG}=\mathrm{MB}>\mathrm{FG}=\mathrm{FB}$ \\
\hline Pressure to eat & $\begin{array}{l}2.87 \\
(.84)\end{array}$ & $\begin{array}{l}3.11 \\
(.77)\end{array}$ & $\begin{array}{l}3.21 \\
(.80)\end{array}$ & $\begin{array}{l}2.85 \\
(.98)\end{array}$ & 1.11 & NS \\
\hline Restriction & $\begin{array}{l}3.34 \\
(.72)\end{array}$ & $\begin{array}{l}3.58 \\
(.87)\end{array}$ & $\begin{array}{l}3.57 \\
(.68)\end{array}$ & $\begin{array}{l}3.39 \\
(.89)\end{array}$ & .620 & NS \\
\hline Drive for Thinness & $\begin{array}{l}3.41 \\
(5.75)\end{array}$ & $\begin{array}{l}3.05 \\
(4.39)\end{array}$ & $\begin{array}{l}1.62 \\
(2.21)\end{array}$ & $\begin{array}{l}.84 \\
(1.61)\end{array}$ & 2.12 & NS \\
\hline Bulimia & $\begin{array}{l}1.24 \\
(1.94)\end{array}$ & $\begin{array}{l}1.21 \\
(2.95)\end{array}$ & $\begin{array}{l}.93 \\
(1.67)\end{array}$ & $\begin{array}{l}.32 \\
(.75)\end{array}$ & .997 & NS \\
\hline Body dissatisfaction & $\begin{array}{l}13.41 \\
(7.94)\end{array}$ & $\begin{array}{l}9.32 \\
(9.05)\end{array}$ & $\begin{array}{l}4.55 \\
(4.30)\end{array}$ & $\begin{array}{l}6.42 \\
(5.82)\end{array}$ & $8.76^{*}$ & $\mathrm{MG}=\mathrm{MB}>\mathrm{FG}=\mathrm{FB}$ \\
\hline $\begin{array}{l}\text { Authoritative } \\
\text { parenting }\end{array}$ & $\begin{array}{l}3.99 \\
(.35)\end{array}$ & $\begin{array}{l}3.96 \\
(.46)\end{array}$ & $\begin{array}{l}3.74 \\
(.53)\end{array}$ & $\begin{array}{l}3.85 \\
(.63)\end{array}$ & 1.48 & NS \\
\hline $\begin{array}{l}\text { Authoritarian } \\
\text { parenting }\end{array}$ & $\begin{array}{l}1.54 \\
(.45)\end{array}$ & $\begin{array}{l}1.56 \\
(.54)\end{array}$ & $\begin{array}{l}1.59 \\
(.42)\end{array}$ & $\begin{array}{l}1.69 \\
(.46)\end{array}$ & .434 & NS \\
\hline $\begin{array}{l}\text { Indulgent/permissive } \\
\text { parenting }\end{array}$ & $\begin{array}{l}1.99 \\
(.65)\end{array}$ & $\begin{array}{l}2.02 \\
(.70)\end{array}$ & $\begin{array}{l}2.14 \\
(.66)\end{array}$ & $\begin{array}{l}2.22 \\
(.70)\end{array}$ & .572 & NS \\
\hline $\begin{array}{l}\text { Years of Education } \\
\text { post } 16\end{array}$ & $\begin{array}{l}5.23 \\
(2.59)\end{array}$ & $\begin{array}{l}4.89 \\
(2.45)\end{array}$ & $\begin{array}{l}4.64 \\
(4.09)\end{array}$ & $\begin{array}{l}5.69 \\
(3.37)\end{array}$ & .443 & NS \\
\hline
\end{tabular}

$* \mathrm{p}<0.0001$

$\mathrm{MG}=$ mothers of girls, $\mathrm{MB}=$ mothers of boys, $\mathrm{FG}=$ fathers of girls, $\mathrm{FB}=$ fathers of boys 
Table 2: Two-tailed Pearson Correlation Coefficients between control variables, parental feeding practices, parenting styles and child BMI Z scores $(\mathrm{N}=96)$.

\begin{tabular}{|c|c|c|c|c|c|c|c|}
\hline & Mon & PTE & Rest & $\begin{array}{l}\text { BMI } \\
\text { Z score }\end{array}$ & Auth'v & Auth' n & Perm \\
\hline Child BMI Z Score & .013 & $-.352 * *$ & .065 & - & .177 & -.131 & -.188 \\
\hline Child age & .083 & .010 & -.048 & -.223 & -.077 & .153 & .172 \\
\hline Parental age & -.048 & .041 & .103 & -.081 & -.049 & .172 & .120 \\
\hline Parental BMI & -.067 & .079 & .171 & .089 & -.137 & .166 & .145 \\
\hline $\begin{array}{l}\text { Duration parents } \\
\text { together (years) }\end{array}$ & .071 & -.215 & -.026 & .040 & -.120 & .080 & -.028 \\
\hline Socioeconomic status & -.137 & .100 & .004 & .196 & $-.225^{*}$ & .006 & .131 \\
\hline $\begin{array}{l}\text { Education post } 16 \\
\text { (years) }\end{array}$ & .129 & -.146 & $-.298 * *$ & -.044 & $.145^{*}$ & -.114 & $-.249 * *$ \\
\hline No of children & -.147 & -.135 & .052 & .177 & .129 & .131 & -.022 \\
\hline $\begin{array}{l}\text { Length of } \\
\text { breastfeeding }\end{array}$ & .048 & .084 & .051 & .063 & -.010 & .072 & -.014 \\
\hline Time spent at nursery & -.073 & .023 & -.061 & -.193 & .090 & .022 & $.291 *$ \\
\hline $\begin{array}{l}\text { Total number of } \\
\text { meals and snacks } \\
\text { spent with child per } \\
\text { week }\end{array}$ & $.403 * *$ & -.001 & .053 & .185 & $.290 * *$ & -.124 & $-.213^{*}$ \\
\hline Drive for thinness & .040 & .138 & .121 & .012 & $-.135^{*}$ & $.320 * *$ & $.293 * *$ \\
\hline Bulimia & -.113 & .058 & .155 & -.075 & $-.286 * *$ & $.422 * *$ & .113 \\
\hline Body Dissatisfaction & .100 & .101 & .059 & -.002 & -.179 & .152 & .195 \\
\hline
\end{tabular}

Mon $=$ monitoring, $\mathrm{PTE}=$ Pressure to Eat, Rest $=$ restriction, Auth'v $=$ authoritative parenting, Auth'n = authoritarian parenting, Perm= permissive parenting. 
Table 3: One-tailed correlation coefficients between parental feeding practices and parenting styles before and after controlling for covariates $(\mathrm{N}=96)$

\begin{tabular}{|c|c|c|c|c|c|c|}
\hline & \multicolumn{3}{|c|}{$\begin{array}{l}\text { Prior to controlling for } \\
\text { covariates (Pearson's } \\
\text { Correlation Coefficients) }\end{array}$} & \multicolumn{3}{|c|}{$\begin{array}{l}\text { After controlling for } \\
\text { relevant covariates (Partia } \\
\text { Correlation Coefficients) }\end{array}$} \\
\hline & Mon & PTE & Rest & Mon & PTE & Rest \\
\hline $\begin{array}{l}\text { Authoritative } \\
\text { parenting }\end{array}$ & $.328 * *$ & -.094 & .001 & $.201 *$ & -.197 & .067 \\
\hline $\begin{array}{l}\text { Authoritarian } \\
\text { parenting }\end{array}$ & -.111 & .101 & .114 & -.039 & .026 & .048 \\
\hline $\begin{array}{l}\text { Permissive/ } \\
\text { indulgent } \\
\text { parenting }\end{array}$ & $-.291 *$ & $.292 * *$ & $.225^{*}$ & $-.301 *$ & $.329 *$ & .164 \\
\hline
\end{tabular}

Mon $=$ monitoring, PTE $=$ Pressure to Eat, Rest $=$ restriction . 